\title{
Breakthrough Paths of Junior Golf in China
}

\author{
Wei Lan ${ }^{1, *}$ \\ ${ }^{1}$ Jinan University, Guangzhou, Guangdong, China \\ ${ }^{*}$ Corresponding author.
}

\begin{abstract}
This paper focuses upon the state of play and issues surrounding the recent development of junior golf in China. By analyzing government documents and data, the paper tried to point out some shortcomings and sought to form a serious of complementary suggestions.

More specifically, despite some solid achievements, there are four primary problems in China junior golf: Firstly, the number of junior golfers is far short than in other developed countries such as the United State and some European countries. Moreover, the number of junior golf events, facilities, and equipment is relatively insufficient, lacking complete systems and mature model. In addition, it is unsatisfactory that governments and schools do not make full use of their resources in cultivating junior golfers. Furthermore, the cooperation between talent junior golfers and the entrance of institutions of higher education is not tight enough which leads to a serious brain drain.
\end{abstract}

Accordance with the extensive evidence, current situation, relevant data, analysis and experience, this article underpins future policy in the following recommendations of reforming sport system, establishing scholarship programs, setting up more collegiate golf events, increasing family participation and providing sufficient equipment. More specific suggestions for each aspect are provided in this advice paper.

Keywords: junior golf, government, school

\section{INTRODUCTION}

It is widely accepted that juniors are the cornerstone of a country. Fraser-Thomas mentioned that sports are an avenue to foster positive junior development which plays a key role in not only Juniors' mental and physical health but also social ability [1]. As a result, the Chinese government has paid more and more attention to juniors' development. With the increasing development of Chinese economic and education, the Chinese government and society have injected considerable effort and resources into junior sports development. Golf, as one of the elite, healthy, technical and leisure sports, it is ushered in the spring [2].

Golf lessons and golf events become more and more popular in China. A Large number of juniors take part in golf. In the meanwhile, China junior golf industry still encounters plenty of difficulties.

This paper provides an overview of the history, current situation and suggestions for junior golf development. Once upon a time, Golf, which is regarded as a kind of noble activity, frequently connected with aristocratic and notions of class [3]. It had been strictly limited in China since 2014, 11 ministries and commissions, including the national development and reform commission and the ministry of land and resources, jointly issued the notice on implementing measures to clean up and renovate golf courses [4].

According to the established calculation model and the basis of the national annual play rounds investigation, the White Paper claimed that the core population in China' golf have maintained for nearly three years, does not have a significant change. The White Paper in 2017 measured that there are 1,000,000$1,100,000$ population taking part in golf in China, of which the core population of about 380,000-390,000. The number of golf play rounds, facilities and the improvement of the population reached a peak in 2014 and then had fallen for two consecutive years. Evidences also showed that there are only 378 perfectly legal golf clubs that are opening in China nowadays [5].

However, thanks to the promulgation of the 13th five-year plan of the sports industry in 2017 [6], There was a turnaround of golf in China. The competitive level of golf has risen rapidly. Furthermore, the golf competition system in China has been preliminarily established. The junior registration system is becoming more and more perfect, with more than 14,000 
registered golfers and over 200 certification events annually, which is in line with the international standard. After the return of golf events to the Olympic Games, golf becomes more potential to achieve full participation in China. Nowadays, the population of golf in China is nearly close to 5 million, and its coverage extends from the high-income to the middleclass step by step [7].

After more than 30 years of development, China has made outstanding achievements in all aspects of golf. More organizations and stakeholders join in this industry. Under this new situation, the development mode especially junior golf is faced with the opportunity and challenge of changing from extensive pursuit of quantity growth to intensive pursuit of quality growth.

\section{UNDERSTANDING OF CHINESE JUNIOR GOLFERS}

\section{A. Definition of junior golfers}

A Chinese junior golfer is a golfer who ages from 6 to 18 and comes from mainland China. In addition, they should have complied with the definition of amateur status in the latest edition of the rules of golf issued by R\&A rules limited and the United States golf association (USGA) [8].

\section{B. Active registered junior golfers}

In order to effectively measure the participation of junior golfers, this paper uses the active registered junior golfers as an index to compare with relevant data. Active registered junior golfers are considered as registered golfers who have participated in a China golf association certified tournament and who earned points in the past two years. It was recorded that the number of active junior registered players greatly outnumbers both professional and amateur golfers, reflecting the popularity of junior golf in China [9].("Fig. 1") At the same time, the brilliant prospect of junior golf also reminds us of the demand for a well-organized management system and strong support by the government.

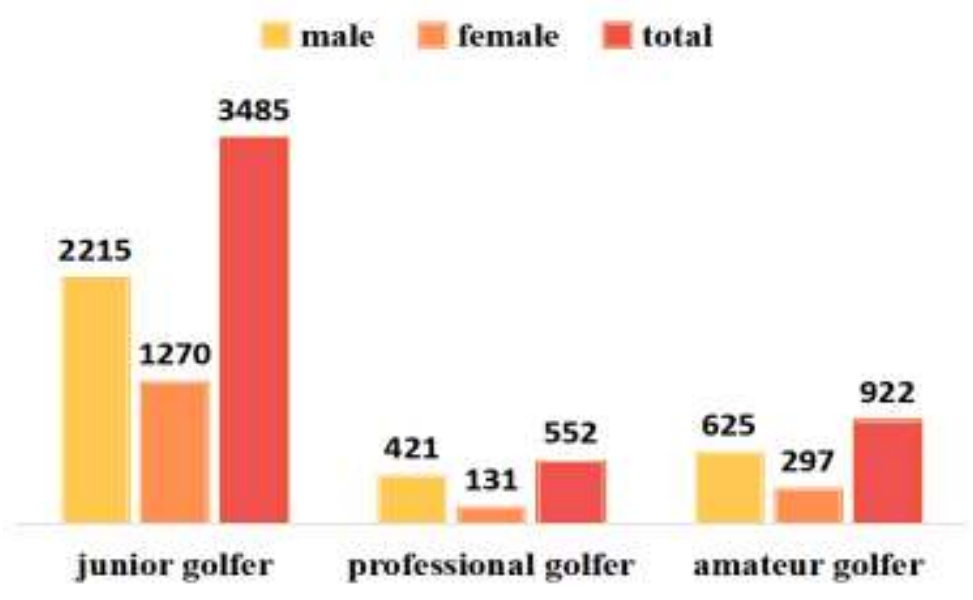

Fig. 1. The number of the active registered golfer in China by 2020 .

\section{Quantity of junior golfers}

As of December 31, 2017, there were 34,572 registered junior golf players in China, with male players accounting for 65 per cent of the total and female players 35 per cent, based on the 2017 annual junior golf data report. As reported by The Sixth National Census, China had a population of $209,403,522$. Juniors aged 6 to 18 , accounting for 16 per cent of the country's total population [10]. Therefore, it is noticed that the junior golfers only make up 0.0165 per cent of China's junior population. With such infinitesimal number of the base of junior players, the development prospect is appreciable broad. Meanwhile, China's junior golf industry still has a long way to go [11]. In recent years, Fraser-Thomas, Strachan, and Jeffery-Tosoni found that parents play a crucial role in junior's involvement, participation and performance in sport [12].

\section{Family environment for junior golfers}

According to surveys about the family influence on junior golfers, 79.8 per cent of junior golfers have family members participating in golf, and only $20.2 \%$ have no other family members participating in golf. Among the participants, fathers accounted for the largest proportion (68.5 per cent), following by mothers (29.8 per cent), siblings (22.5 per cent) and relatives (16.3 per cent) [13]. ("Fig. 2") 


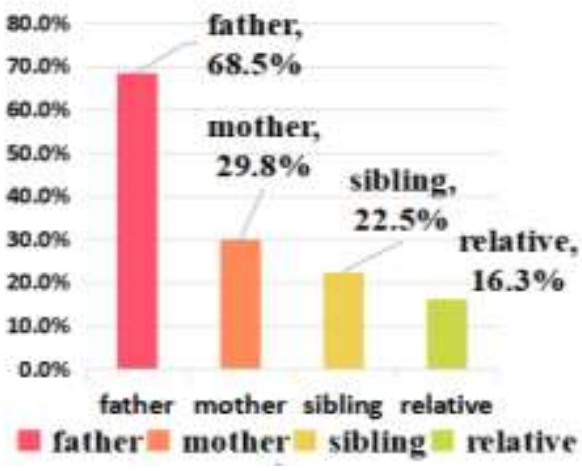

Fig. 2. The proportion of family members in golf participation.

\section{Problems of JUnior golf In China}

\section{A. Lack of junior golfers}

It has been mentioned above that China has 34,572 registered junior golf players and 350,000 registered adult golfers. Registered junior golfers account for $9.87 \%$ of the total registered players.

Compared with Europe, there were 331,391 registered juniors golfers in 2017, which occupied 8 per cent of the total number of registered golfers [14]. When it comes to the United State, according to the research from the National Golf Foundation, 2,500,000 Juniors played golf on a course in 2018, remaining relatively stable in relation to recent years, with the participation base fluctuating between 2.5 million and 3 million [15], accounting for $7.46 \%$ of the total golfers in the USA.

Apparently, the percentage of junior golfers in the United State and Europe is considered higher than in China.

\section{B. Short of facilities and equipment}

By March 2017, China golf association had certified 113 China golf junior training bases [16]. According to the certification standards, each of the 113 junior training bases (including golf courses and driving ranges) must provide no less than 400 hours of free training per year to junior players. From another point of view, basing on the number of registered junior golfers in China, an average of one hour per day is required for free training for junior golfers at each junior training bases. On average, each junior training base must provide free training spaces for 306 registered junior golfers per day. In addition, the spatial distribution of those training bases is uneven, concentrating in the economically developed southeast coastal areas. It is clear that the free training bases are insufficient and partial, which will increase the difficulties and the cost of training.

\section{Imperfect systems and immature model}

The development of golfers in the United State is a typical social management system. Under the U.S. amateur sports act of 1978, the federal government just providing certain financial support but do not interfere with each sports agency's management [17]. Basically, Sports management agencies manage their relevant affairs independently. The power of the government in the development of sports is limited to a minimum. In this system, market plays a significant role in daily operation, training system and event affairs. On the contrary, the public government of China controls the sports agencies and limits the impact of markets, which leads to a serious of problems.

\section{Serious brawn drain}

In 2015, elite athletes were exempted from college entrance exams and were allowed to play golf as a kind of college entrance exam for the first time. In 2016, golf was included in the national unified examination system for sports training, martial arts, and traditional ethnic sports in colleges and universities.

According to the statistical table of sports grades in the report, a total of 482 people in the national golf program have sports grade titles. After obtaining sports grade titles, junior golfers have the quality to attend college entrance exams by playing golf.

In 2017, a total of 48 students from 11 provinces and municipalities across the country participated in the exam, with 28 students were admitted. The passing rate was nearly 58 per cent. And 5 of them were accepted by the comprehensive universities, other 23 junior players entered in Sport University. In 2018, a total of 40 junior golfers passed the golf entrance exam and five of them were endorsed as 'matriculation exempt', with 11 of them enter comprehensive university [18].

Comprehensive universities and sports Universities are significantly different in teaching quality, academic level and career development in China. Students in sports universities pay more attention to sports rather than academic performance, which causes the weakness of knowledge and academic capability. That is to say, inevitably, their educational background would not be widely accepted. It is bad for their further education. As a result, junior golfers in China who pursue a highquality and long-term education will be caught in a dilemma. A large number of junior golfers may dropout in order to concentrate on study. It causes a serious talent drain. And even though some juniors insist on golf and enter into sports colleges, the short of education has a negative impact on their future development.

On the contrary, the junior golfers in the United State have more choices. NCAA (The National Collegiate Athletic Association) is a member-lead 
organization dedicated to the well-being and lifelong success of college athletes. The universities and colleges connected with the NCAA have a high reputation. More importantly, there are no privileges for every college athlete. All the college athletes required to balance academic performance and golf performance, otherwise they could be punished by suspension.

\section{E. Insufficient junior golf events}

In 2017, a total of 273 junior golf events were declared and 185 were held, with a completion rate of

junior event

collegiate event

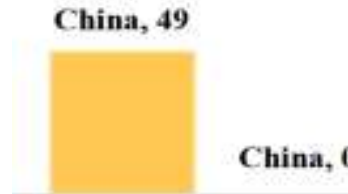

China

Fig. 3. The number of junior and collegiate golf events

\section{F. Costly junior golf events}

In December 2017, Dazheng Golf conducted a questionnaire survey on junior golfers, including a total of 2,819 valid questionnaires, from which relevant data were obtained. The survey found that the top three spending items for junior golfers in the past year were attending events, buying equipment and buying golf clubs.

To a large extent, the development of junior golf is closely related to the scale, quality, venue and social recognition of the golf events [20]. At present, junior golf competitions are mostly concentrated in developed regions such as the pearl river delta, the Yangtze river delta, and the Beijing-Tianjin-Hebei region. And juniors athletes often participate in golf events with their parents which increases the accommodations and traffic fees. In addition, a majority of junior golf events are commercial events, junior golfers need to pay a large amount of Application fee. The high cost deters junior golfers from participating in more golf events.
$68 \%$. The total number of visitors reached to 250,000 , an increase of 30,000 from 2016. However, there are only 49 national competitions have been certified by the WAGA (World Amateur Golf Ranking) for junior golfers in 2020. Furthermore, there is a lack of formal regional competitions and collegiate golf events.

In comparison with America, According to the WAGA, there are 75 junior golf events and 157 collegiate golf competitions in 2020 [19], which is far more golf events than China. ("Fig. 3")

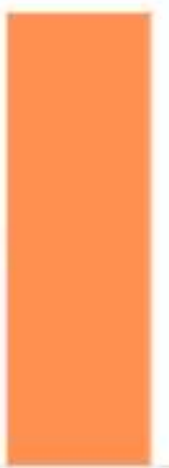

the United State

the United State, 75

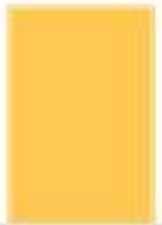

\section{Suggestion}

\section{A. Sport system reform}

Aiming at solving the problems mentioned above, it is high time to reform the Chinese sports system. In addition to granting more autonomy and authority to sports departments, sports agencies and professional union system should be supported. Rather than controlling the operation and management of sports agencies, the government should only takes charge of indirect supervision and inspection of macro policies and regulations. Sports unions and sports agencies should make full use of the power of the market by selling television rights, obtaining more sponsor and so on. In use of the benefit of market regulation to coordinate the interests of spectators, players, professional teams, leagues, media, sponsors and governments. More healthy and sustainable development of the sports industry can be driven.

\section{B. School cooperation}

By learning from the cultivation of competitive golf talents in the United State, the public government of China should concentrate on Schools, forming the cultivation mode which mixes school alliance with 
professional alliance. Golf talents can follow the path which established by sports agencies of government, from primary school to university then finally join in professional club.

Schools should set up a long-term development target. In the first phase, focus on the cultivation of interest and popularize knowledge of golf. By carrying out a wide range of campus golf activities, lay a solid foundation of physical health. In the second phase, golf could be a course in middle and junior schools, systematic golf skills can be taught in class. Select some talent golfers into school teams, providing them more professional training. In the third phase, the most crucial stage, golfers enter into universities or colleges, and it is the time that they can decide whether to become a professional golfer. A national collegiate athletic association should be set up in order to manage college golfers, providing them more opportunities to have scientific training. Well-educated collegiate golfers are more potential and promising especially when they become professional golf athletes [21]. It could form a positive circle and promote the golfers' development.

\section{Scholarship program and collegiate golf events}

In order to encourage junior golfers to participate in golf events and relieve the financial burden, the government could set up a scholarship program for junior golfers who join the golf events. For example, Progress Award, Minimum shot in a single round award, the most diligent award and so on. In addition, more charitable golf events should behold aiming at support more junior golfers to golf events.

In terms of golf events, collegiate golf events should be established. It can be divided into two main parts. In the first stage, the collegiate golf event can be split into two divisions: the north and south division. In the second stage, the national collegiate events should be set up for excellent players from the north and south divisions.

At the same time, the continuous expansion of the scale of the events and the continuous improvement of the quality of the event should also become the focus of future work, striving to create a high social recognition, junior golf events with Chinese characteristics. More high-quality events are established, more channels for junior golfers to improve their athletic abilities and athletics performance.

\section{Family participation and sufficient equipment}

In order to inspire more juniors to participate in golf, sufficient equipment and golf clubs are essential. More free diving ranges and courses provide juniors more opportunities to deeply understand the charm of golf and support them insist on golf.
Enhancing family participation in golf is also an effective method that can cultivate golf habits and provide a positive environment for juniors to participate in Golf. Golf can become a leisure family activity for all family members to reunion together. It can not only building the body but also enhance relationships.

\section{CONCLUSION}

Overall, this paper briefly summarizes the situation of Junior golf in China, points out some aspects for improvement. The junior golf industry plays a significant role in the Chinese golf industry as well as the whole sports industry. It has a promising future and could be a kind of sport dividend as long as the government spares no efforts to support it. By a serious of methods such as reforming the traditional sport system, establish scholarship programs and collegiate golf events and so on, junior golf could have a breakthrough in the near future.

\section{References}

[1] J. Fraser-Thomas, J. Côté and J. Deakin, "Youth sports programs: an avenue to foster positive youth development," Physical Education \& Sport Pedagogy, vol. 10, no. 1, pp. 19-40, 2005.

[2] W. Vamplew, "Concepts of Capital: An Approach Shot to the History of the British Golf Club before 1914," Journal of Sport History, vol. 39, no. 2, pp. 299-331, 2012

[3] H. Ceron-Anaya, "An Approach to the History of Golf: Business, Symbolic Capital, and Technologies of the Self, "Journal of Sport and Social Issues, vol. 34, no. 3, pp. 339-358, 2010.

[4] General Administration of Sport of China, "junior sports 13th five-year plan," Sport.gov.cn, 2016. [Online].

[5] Forward Management Group, "White Paper of China golf industry report," Forwardgolf.com.cn, 2018. [Online] Available: http://www.forwardgolf.com.cn/electronic.asp.

[6] General Administration of Sport of China, "junior sports 13th five-year plan," Sport.gov.cn, 2016. [Online].

[7] Forward Management Group, "White Paper of China golf industry report," Forwardgolf.com.cn, 2018. [Online].

[8] "China golf association official website youth skill level", Cgagolf.org.cn, 2020. [Online].

[9] "Registered Golfers in China," Cgagolf.org.cn, 2020. [Online]. Available: http://www.cgagolf.org.cn/column/158/.

[10] "The Sixth National Census," Stats.gov.cn, 2010. [Online]. Available: http://www.stats.gov.cn/tjsj/pcsj/rkpc/6rp/indexch.htm.

[11] "2017 annual youth golf data report," Bwvip.com, 2020 [Online]. Available: http://www.bwvip.com/default.php?g=m\&m=arc\&a=arc_detail \&arc_id=39934. [Accessed: 19- Apr- 2020].

[12] J. Fraser-Thomas, L. Strachan, S.Jeffery-Tosoni, "Family influence on children's involvement in sport," In Conditions of Children's Talent Development in Sport, Fitness Information Technology: Morgantown, MV, USA, pp. 179 - 196, 2013.

[13] "2017 annual youth golf data report," Bwvip.com, 2020 [Online] 
http://www.bwvip.com/default.php?g=m\&m=arc\&a=arc_detail \&arc_id=39934.

[14] "Golf Participation Report for Europe 2018," Assets.KPMG,
2018.
[Online].
Available:

https://assets.kpmg/content/dam/kpmg/xx/pdf/2018/11/golfparticipation-report-for-europe-2018.pdf.

[15] "Golf Research and Industry Data, "Ngf.org, 2020. [Online]. Available: https://www.ngf.org/golf-industry-research/.

[16] "The 13th five-year plan for the development of golf", China Golf Association, 2017.

[17] "The Amateur Sports Act of 1978," GovTrack.us, 2020. [Online]. Available: https://www.govtrack.us/congress/bills/95/s2727/text.

[18] "A separate entrance exam for golf," Bwvip.com, 2020. [Online]. Available: http://www.bwvip.com/default.php?g=m\&m=arc\&a=arc_detail \&arc_id=40808.

[19] "Junior Events \& Collegiate Events," World Amateur Golf Ranking, 2020.

[20] L.Yi, "Study on influencing factors of young golf players in China", Contemporary sports science and technology, 7(24):198-201.R, 2017.

[21] J.Wang, "Enlightenment of foreign golf talent training for China," Shandong sports science and technology, 40(04):40-46, 2008 . 